\title{
Using vignettes to assess the contribution of goal adjustment in the adaptation to chronic musculoskeletal pain
}

Citation for published version (APA):

Lopez-Martinez, A. E., Ramirez-Maestre, C., Serrano-lbanez, E. R., Ruiz-Parraga, G. T., Peters, M. L., \& Esteve, R. (2020). Using vignettes to assess the contribution of goal adjustment in the adaptation to chronic musculoskeletal pain. Quality of Life Research, 29(8), 2137-2148. https://doi.org/10.1007/s11136020-02487-5

Document status and date:

Published: 01/08/2020

DOI:

10.1007/s11136-020-02487-5

Document Version:

Publisher's PDF, also known as Version of record

Document license:

Taverne

Please check the document version of this publication:

- A submitted manuscript is the version of the article upon submission and before peer-review. There can be important differences between the submitted version and the official published version of record.

People interested in the research are advised to contact the author for the final version of the publication, or visit the DOI to the publisher's website.

- The final author version and the galley proof are versions of the publication after peer review.

- The final published version features the final layout of the paper including the volume, issue and page numbers.

Link to publication

\footnotetext{
General rights rights.

- You may freely distribute the URL identifying the publication in the public portal. please follow below link for the End User Agreement:

www.umlib.nl/taverne-license

Take down policy

If you believe that this document breaches copyright please contact us at:

repository@maastrichtuniversity.nl

providing details and we will investigate your claim.
}

Copyright and moral rights for the publications made accessible in the public portal are retained by the authors and/or other copyright owners and it is a condition of accessing publications that users recognise and abide by the legal requirements associated with these

- Users may download and print one copy of any publication from the public portal for the purpose of private study or research.

- You may not further distribute the material or use it for any profit-making activity or commercial gain

If the publication is distributed under the terms of Article 25fa of the Dutch Copyright Act, indicated by the "Taverne" license above, 


\title{
Using vignettes to assess the contribution of goal adjustment in the adaptation to chronic musculoskeletal pain
}

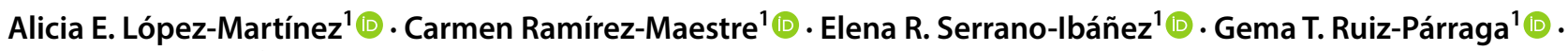 \\ Madelon L. Peters ${ }^{2}$ (i) $\cdot$ Rosa Esteve ${ }^{1}$ (D)
}

Accepted: 17 March 2020 / Published online: 31 March 2020

(c) Springer Nature Switzerland AG 2020

\begin{abstract}
Purpose The quality of life of individuals with chronic musculoskeletal pain partly depends on their capacity to adjust their personal goals. Vignettes have been rarely used to assess this ability. Therefore, this study aimed to test the relationships between vignettes assessing different goal strategies and chronic pain adaptation (i.e., daily functioning, pain-related impairment, and psychological well-being).

Methods The sample comprised 258 individuals with chronic musculoskeletal pain who completed a series of questionnaires and vignettes. The vignettes presented a short description of a situation in which a person with chronic pain experienced a threat to a valued domain-specific goal and had to choose a possible goal management solution (i.e., goal persistence, flexibility reengagement, and disengagement). Hierarchical regression analyses were used to predict chronic pain adaptation using the selected vignette strategies as predictors.

Results After controlling for age, sex, pain intensity, and the responses to the dispositional goal management scales, persistence, reengagement, and disengagement goal strategies presented in the case scenarios predicted daily functioning $(p<.001)$. Persistence, flexibility, disengagement $(p<.001)$, and reengagement $(p<.05)$ predicted pain-related impairment. Persistence, disengagement $(p<.001)$, and flexibility $(p<.05)$ predicted psychological well-being scores.

Conclusion The use of vignettes could be useful to assess goal adjustment because this methodology enables respondents to provide more context-specific responses. The results of this approach could be used to improve clinical practice aimed at helping people with chronic musculoskeletal pain to better cope with this health condition.
\end{abstract}

Keywords Chronic musculoskeletal pain $\cdot$ Goal adjustment $\cdot$ Domain-specific vignettes $\cdot$ Pain adaptation

\section{Introduction}

Electronic supplementary material The online version of this article (https://doi.org/10.1007/s11136-020-02487-5) contains supplementary material, which is available to authorized users.

Alicia E. López-Martínez

aelm@uma.es

1 Departamento de Personalidad, Evaluación y Tratamiento Psicológico, Instituto de Investigaciones Biomédicas de Málaga (IBIMA), Facultad de Psicología, Universidad de Málaga, Campus de Teatinos, 29071 Málaga, S/N, Spain

2 Department of Psychology and Neuroscience, Clinical Psychological Science, Behavioural Medicine, Maastricht University, Maastricht, The Netherlands
The ability to adjust goals is an adaptive self-regulation strategy that is relevant to the well-being of individuals with chronic pain [1]. Musculoskeletal (MSK) pain is one of the most common diagnoses of chronic pain [2]. Chronic pain conditions affecting the musculoskeletal system are multifaceted, often have no cure, and can result in severe disability and distress because they are associated with reduced activity, fatigue, and mood alterations, among other effects. Consequently, chronic MSK pain interferes with daily activities and goals. Evidence suggests that the level of quality of life partly depends on the capacity to adjust personal and life goals [3, 4]. It is, therefore, not surprising that there is a growing empirical literature on the degree to which pain goals interfere with daily life goals. This literature has been motivated by the fact that individuals with chronic MSK 
pain experience significant goal disruption and are thus at an increased risk of encountering unattainable goals [5-9].

From the perspective of personality theory, it has been argued that there are individual differences in dispositionalgoal adjustment capacities [10] (i.e. in behaviour aimed at managing specific unattainable goals). However, research is scarce on the relationship between these capacities and the processes that take place when individuals with chronic MSK pain confront unattainable goals. Similarly, there have been few studies on the utility of domain-specific measurements aimed at assessing the dispositional-goal adjustment capacities of individuals.

Domain-specific vignettes are well-suited to the investigation of daily-life situations and can be used to study potential differences between situational and dispositional goaladjustment capacities [11]. The special design of vignettes enables the simultaneous presentation of several explanatory and contextual factors that represent realistic scenarios [12]. Although the use of vignettes in the field of chronic pain is gaining attention [13, 14], this methodology has been rarely used to assess goal adjustment, except in a few studies. For instance, Arends et al. $[15,16]$ examined goal management strategies and indicators of adaption to living with polyarthritis. Framed within a dual process $[17,18]$ and goal adjustment [19] models, which Arends et al. [15] named the integrated model of goal management, these authors investigated how people with polyarthritis under threat used four different goal strategies: (1) maintenance (the strategy intended to attain a goal), (2) adjustment (a more suitable strategy when goals are under threat), (3) disengagement (as a facet of the broader goal adjustment strategy), and (4) reengagement (a strategy to complement existing goals or replace unattainable goals). They found an association between better adaptation and the tendency to adjust goals to personal abilities and circumstances [16]. However, they did not address the predictive value of their vignettes in relation to successful adaptation and well-being, nor did they compare dispositional questionnaires and domain-specific vignettes. Furthermore, a recent study [6] investigated the association between the aforementioned goal-management strategies and activity patterns. The authors found that pain management strategies were not directly associated with activity patterns. They suggested that these findings could be due to the type of measurements used in their study (i.e. dispositional questionnaires) and that future studies could use other assessment tools such as vignettes.

Therefore, this study is based on the hypothesis that the responses of individuals with chronic MSK pain to vignettes showing a realistic and recognisable situation in which a valued goal is threatened could help to understand how they cope with setbacks in the process of goal striving and to guide interventions towards more suitable pain-related goals that will improve their quality of life.
The present study takes as its starting point the aforementioned integrated model of goal management proposed by Arends et al. [15]. The aim was to test the independent contribution of the responses to situational measures (i.e. vignettes) to their level of daily functioning, pain-related impairment, and psychological well-being after controlling for demographic variables (age and sex), pain intensity, and the effects of the responses to dispositional measures (i.e. self-report questionnaires) in individuals with chronic MSK pain. It was assumed that the vignette would allow the participants to distance themselves from personal experiences or the situations described in the stories and to interpret case scenarios from the perspective of the vignette characters [20]. In addition, it was considered that the use of vignettes could be useful when pain-related goals management is considered to affect quality of life. Thus, it was expected that the response to vignettes showing situations related to the adaptive management of pain-related goals (i.e., goal reengagement, goal persistence, and flexibility responses) would significantly and positively predict higher daily functioning, less pain-related impairment, and higher levels of psychological well-being. On the other hand, given that a recent study has suggested that disengagement may be beneficial only when it is accompanied by reengagement [1], it was expected that strategies aimed at disengaging from unreachable goals would be associated with worse pain adjustment.

\section{Methods}

\section{Participants and procedure}

The sample comprised 258 individuals with chronic pain (249 females and 29 males). The average age was 52.45 years (SD 9.76). Participants were recruited from the pain units of two general hospitals and from several fibromyalgia associations. The inclusion criteria were: (1) age 18 to 65 years; (2) no significant health or psychological problems other than chronic pain; (3) an average pain intensity score of 3 or more on a scale ranging from 0 to 10 ; and (4) the ability to understand the instructions and the questionnaires. Participants were informed of the study aims, confidentiality was assured, and written informed consent was obtained in accordance with the Declaration of Helsinki. This study formed part of a larger research project which was approved by the University of Málaga (Spain) Ethics Committee. All participants had a semi-structured interview with a trained psychologist to obtain demographic, social, and medical history data. Subsequently, they completed the questionnaires and vignettes described in the Measures section. The vignettes were included at the end of the battery of questionnaires. 


\section{Measures}

All participants were asked to provide information on age, gender, marital status, highest educational level completed, and employment status. They also provided information on pain duration and frequency.

\section{Composite pain index}

Pain intensity was assessed according to the recommendations of Jensen et al. [21], patients were asked to rate their lowest, medium, and strongest pain during the previous week, as well as their current pain, on a scale ranging from 0 (not at all) to 10 (extremely painful). The mean of these four scores was calculated to obtain a composite pain intensity score.

\section{The goal disengagement and goal reengagement scale}

The Spanish version of this scale [22] is a 10-item instrument that comprises a 5-point Likert-type scale ranging between 1 (almost never true) and 5 (almost always true). It has adequate criterion validity, internal consistency, and stability and its factor structure is similar to the original structure [19]. It measures the individual's usual reaction to having to stop pursuing an important goal. Four items measure the tendency to disengage from unattainable goals and 6 item measure the tendency to reengage with new goals. In this study, the Goal Disengagement and Goal Reengagement subscales had Cronbach's alphas of 0.71 and 0.94, respectively. These values are similar to those obtained in previous studies on individuals with chronic MSK pain [6].

\section{The tenacious goal pursuit and flexible goal adjustment scale}

The Spanish version of this scale [22] is a 29-item tool that comprises a 5-point Likert scale ranging from 1 (fully disagree) to 5 (fully agree). It assesses two distinct modes of coping with goal disruption: tenacious goal pursuit, and flexible goal adjustment. The psychometric properties of this scale are similar to the original questionnaire [17]. In this study, the Tenacious Goal Pursuit and Flexible Goal Adjustment subscales had Cronbach's alphas of 0.79 and 0.80 , respectively. These values are similar to those obtained in previous studies on individuals with chronic MSK pain [6].

\section{The impairment and functioning inventory revised}

This scale [23] is a 30-item measure that assesses specific activity associated with autonomous behaviour, household activities, social relationships, and leisure in individuals with chronic pain. The participants indicate how many times they performed an activity during the previous week on a 5 -point scale ranging from 0 (never) to 4 (10 or more times). If an activity was not performed, they indicate if this was due to pain. Functioning and impairment were respectively calculated by summing the frequencies of each activity and the total number of activities that the participant did not perform because of pain. This approach is useful in assessing patients with a long history of pain. In this study, daily functioning and pain-related impairment had Cronbach's alphas of 0.87 and 0.87 , respectively. These values are slightly lower than those obtained in previous Spanish studies on people diagnosed with chronic MSK pain [23].

\section{The World Health Organization psychological well-being index}

The Spanish version of this scale [24] is a 5-item measure in which respondents indicate how they have been feeling during the last 2 weeks on a scale ranging from 0 (at no time) to 5 (all of the time). In the present study, Cronbach's alpha was 0.90 , a higher value than reported in other study with a similar sample [25].

\section{Case vignettes}

Three scenarios with a short description of a situation in which a person with chronic pain experienced a threat to a valued domain-specific goal and had to make a decision were presented to participants. The scenarios were developed in accordance with the recommendations of this assessment methodology [12]. The scenarios addressed three domains (i.e. social, leisure activity, and independent functioning). For every domain, a vignette presented a description of a specific situation. Each domain had four response options, each of which presented a possible solution that employed one of the four goal management strategies (i.e. goal reengagement, goal disengagement, goal persistence, and flexibility). An example of a vignette is available as supplementary material.

For each vignette, the participants were asked to rate every possible solution that the main character could try on a scale ranging from 1 (not good at all) to 4 (very good). Subsequently, to ensure their external validity, the vignettes were described again and the participants were asked to rate to what extent they would try each of the solutions on a scale ranging from 1 (I would never try this) to 4 (I would always try this). The three vignettes were included at the end of the battery of questionnaires and were always presented to the participants in the same randomised order (first the social scenario, then the leisure activity scenario, and finally the independent functioning scenario), whereas the order of presentation of each solution strategy was balanced between vignettes. 


\section{Statistical analyses}

All analyses were conducted using the Statistical Package for Social Sciences (SPSS; Windows version 25.0, SPSS Inc., Chicago, IL). Descriptive statistics were calculated for the demographic, clinical, and other variables considered in the study. Bivariate correlations were calculated to investigate the relationships between every vignette score for both types of response and goal-management dispositional-scale scores (i.e. goal disengagement, goal reengagement, tenacious goal pursuit, and flexibility). Correlations were interpreted following the guidelines proposed by Cohen [26]. A series of hierarchical regression analyses were conducted, one for each criterion variable (i.e. daily functioning, pain-related impairment, and well-being) and for each of the four goalmanagement options. The variables and their distributions were tested for normality, homoscedasticity, and multicollinearity to ensure that they met the assumptions for the regression analyses [27]. In each analysis, we first entered demographic data (age, sex) and pain intensity as control variables (step 1). We then entered the scores in the goalmanagement dispositional subscales (step 2). Finally, in step
3 , the participants' responses to the vignettes were entered. For this purpose, the participants' responses regarding the extent to which they would try each of the goal-management strategies in every vignette were computed as one variable by calculating the mean of the scores. Figure 1 summarizes the analytical approach.

\section{Results}

\section{Sample characteristics}

At the time of the study, $72 \%$ of the participants were married or cohabiting. In total, $40 \%$ and $33 \%$ had completed primary and high school education, respectively. Regarding work status, $39 \%$ were active workers, $24 \%$ were retired, $23 \%$ were unemployed, and $14 \%$ were housewives. Median pain duration was 12 years (SD 9.76). The participants had chronic MSK pain of different aetiologies with the most frequent being fibromyalgia (28\%) and spinal pain (26\%). The median pain duration was 12 years (SD 9.76), and the average pain intensity was 6.50 (SD .40).
Fig. 1 Summary of the analytical approach used to perform the series of hierarchical regression analyses. ${ }^{a}$ Each dispositional subscale and its corresponding situational measure (vignette) were regressed separately in the analysis

\section{Criterion variables}

Daily functioning

Impairment

Psychological well-being

Control variables. Entered in step 1

Age

Sex

Pain intensity

Predictor variables. Goal-management dispositional subscales. Entered in step 2

Tenacious Goal Scale ${ }^{\mathrm{a}}$

Flexible Goal Scale

Goal Disengagement Scale

Goal Reengagement Scale

Predictor variables. Participants' responses to the vignettes. Entered in step 3

Persistence strategy $^{\mathrm{a}}$

Flexibility strategy

Disengagement strategy

Reengagement strategy 


\section{Means, standard deviations, and bivariate correlations between situational (vignettes) and dispositional measures}

Table 1 shows the descriptives and bivariate correlations between both types of response to the vignettes and the goalmanagement dispositional subscales.

Dispositional measures were significantly inter-correlated, with moderate values ranging from - .59 (between responses to the Tenacious Goal Pursuit and the Goal Disengagement scales) to -.31 (between responses to the Flexible Goal Adjustment and the Goal Disengagement scales). High correlations were found between both types of response to vignettes (i.e. participants and characters responses) for every goal management strategy. In all cases, low to moderate inter-correlations were found between the vignettes and the dispositional measures, with values ranging from .13 (for reengagement as the participants' option) to .37 (for disengagement as the participants' option). The only exception was the reengagement option in the main character vignette. This option was not correlated with the Goal Reengagement Scale (.04).

In relation to the main character responses to the vignettes, significantly low to moderate inter-correlations were found between the responses to the goal management strategies presented in the vignettes and the responses to the dispositional goal management scales (with values ranging from .14 for goal flexibility and .37 for goal disengagement). In relation to the participants' own responses to the vignettes, significantly low to moderate inter-correlations were found between the responses to the goal management strategies presented in the vignettes and the responses to the dispositional goal management scales (with values ranging from .13 for goal reengagement and .35 for goal disengagement).

\section{Multiple regression analyses}

The results of the assumptions testing show that the skewness (range -1.42 to 1.09 ) and kurtosis (range -.68 to 2.80 ) values did not exceed the standard cutoff of 3 [27], indicating that study variables had normal distributions and were thus adequate for the regression analyses. The lack of multicollinearity between the predictor variables was confirmed by variance inflation factors, as their values (range 1.02 to 2.26 in the regression analyses) were substantially below the standard cutoff of 10. In addition, Durbin-Watson' values were between 1.74 and 2.11 for the criterion variables.

\section{Goal management strategies as predictors of daily functioning}

Table 2 presents the results of multiple regression analyses predicting daily functioning. After controlling for

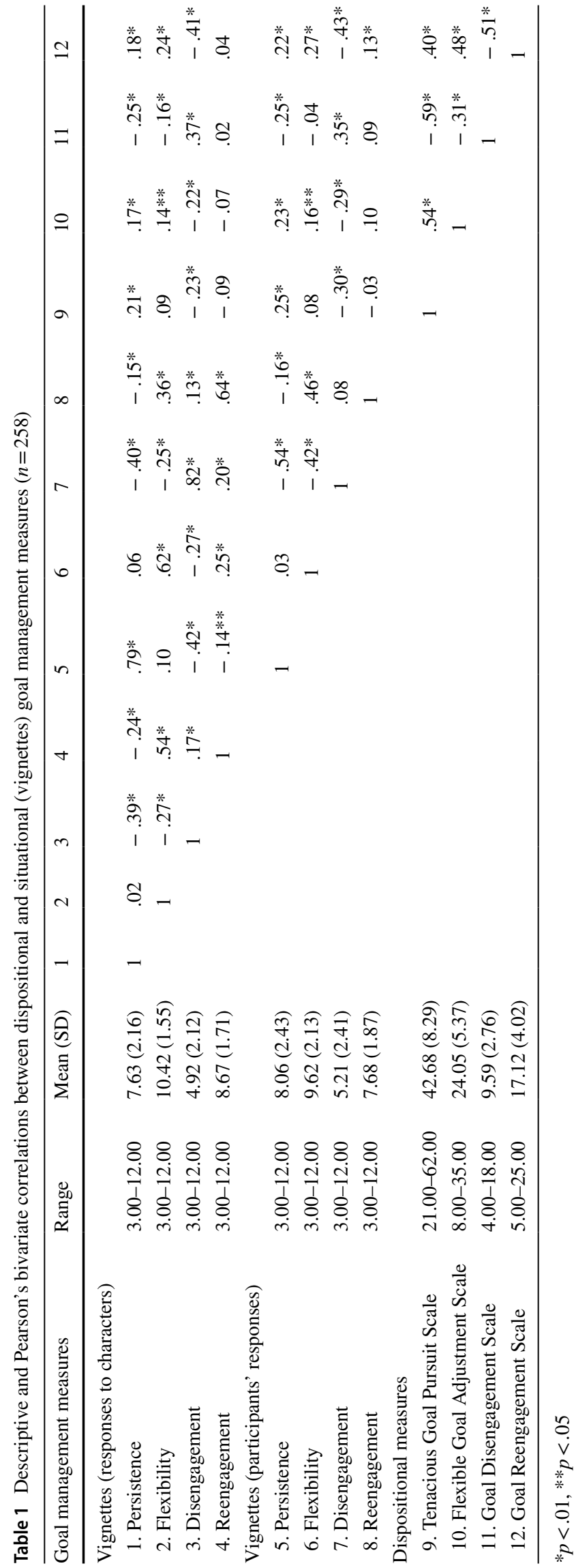


demographic variables (age and sex) and pain intensity (entered in step 1), all variables in the analyses entered in step 2 (the scores of dispositional measures) and in step 3 (goal strategies of vignettes) significantly contributed to daily functioning scores. The only exception was the situational flexibility goal strategy. When pain intensity $(\beta=-0.33, p<.001)$ and dispositional persistence (i.e. Tenacious Goal Scale scores; $\beta=-0.24, p<.001$ ) were controlled, the situational persistence goal strategy $(\beta=0.29$, $p<.001$ ) made an additional and significant contribution to the prediction of daily functioning. The higher the persistence strategy scores, the higher the daily functioning scores. The disengagement goal strategy (i.e. Goal Disengagement Scale; $\beta=-0.28, p<001)$ also predicted daily functioning after controlling for pain intensity $(\beta=-0.31, p<.01)$ and dispositional disengagement $(\beta=-0.22, p<.01)$. The lower the disengagement strategy scores, the higher the daily functioning scores. Surprisingly, a negative association $(\beta=-0.27, p<.001)$ was found between reengagement goal strategy and daily functioning after controlling for pain intensity $(\beta=-0.32, p<.001)$ and dispositional reengagement (i.e. Goal Reengagement Scale; $\beta=0.27, p<0.001$ ). After controlling for pain intensity $(\beta=-0.32, p<.001)$ and dispositional flexibility (i.e. Flexible Goal Scale; $\beta=0.27$, $p<.001$ ), the situational flexibility goal strategy did not make a significant contribution to daily functioning scores. Age and sex were not entered in any of the equations to predict daily functioning.
Table 2 Results of multiple regression analyses predicting daily functioning

\begin{tabular}{|c|c|c|c|c|c|}
\hline Step and variables & Total $R^{2}$ & $\Delta R^{2}$ & $F$ for model & $\mathrm{B}[95 \% \mathrm{CI}]$ & $\beta$ \\
\hline Step 1 & .132 & & $14.08 * *$ & & \\
\hline Age & & & & & $-.03^{\mathrm{a}}$ \\
\hline Sex & & & & & .10 \\
\hline Pain intensity & & & & $-3.24[-4.27,2.21]$ & $-.33 * *$ \\
\hline Step 2 & .224 & 0.09 & & & \\
\hline Tenacious Goal Scale & & & & $.38[.20, .563]$ & $.24 * *$ \\
\hline Step 3 & .297 & 0.07 & & & \\
\hline Persistence strategy ${ }^{\mathrm{b}}$ & & & & $1.63[1.01,2.24]$ & $.29 * *$ \\
\hline \multicolumn{6}{|l|}{ Step 1} \\
\hline Age & & & & & -.00 \\
\hline Sex & & & & & .13 \\
\hline Pain intensity & & & & $-3.12[-4.23,-2.01]$ & $-.31 * *$ \\
\hline Step 2 & .207 & 0.08 & & & \\
\hline Flexible Goal Scale & & & & $.69[.40, .98]$ & $.27 * *$ \\
\hline Step 3 & .212 & 0.01 & & & \\
\hline Flexibility strategy ${ }^{\mathrm{b}}$ & & & & & .09 \\
\hline \multicolumn{6}{|l|}{ Step 1} \\
\hline Age & & & & & .03 \\
\hline Sex & & & & & .10 \\
\hline Pain intensity & & & & $-3.19[-4.25,-2.14]$ & $-.32 * *$ \\
\hline Step 2 & .229 & 0.10 & & & \\
\hline Goal Disengagement Scale & & & & $-1.08[-1.63,-.51]$ & $-.22 * *$ \\
\hline Step 3 & .293 & 0.07 & & & \\
\hline Disengagement strategy ${ }^{\mathrm{b}}$ & & & & $-1.57[-2.22,-.92]$ & $-.28 * *$ \\
\hline \multicolumn{6}{|l|}{ Step 1} \\
\hline Age & & & & & .02 \\
\hline Sex & & & & & .11 \\
\hline Pain intensity & & & & $-3.24[-4.34,-2.14]$ & $-.32 * *$ \\
\hline Step 2 & .185 & 0.06 & & & \\
\hline Goal Reengagement Scale & & & & $.87[.48,1.25]$ & $.27 * *$ \\
\hline Step 3 & .210 & 0.03 & & & \\
\hline Reengagement strategy ${ }^{\mathrm{b}}$ & & & & $-1.27[-2.09,-.45]$ & $-.17 *$ \\
\hline
\end{tabular}




\section{Goal management strategies as predictors of pain-related impairment}

Table 3 presents the result of multiple regression analyses predicting pain-related impairment. After controlling for demographic variables (age and sex) and pain intensity, all the variables in the analysis significantly contributed to the scores of the pain-related impairment criterion. After controlling for $\operatorname{sex}(\beta=0.13, p<.05)$, pain intensity $(\beta=0.25$, $p<.001)$, and dispositional persistence $(\beta=-0.21$, $p<.001)$, the persistence goal strategy $(\beta=-0.43 p<.001)$ made an additional significant contribution to the prediction of pain-related impairment. The lower the persistence strategy scores, the higher the impairment scores. Similar results were obtained for flexibility $(\beta=-0.20, p<.001)$ after controlling for pain intensity $(\beta=0.25 p<.001)$ and dispositional flexibility $(\beta=-0.19, p<.05)$. Disengagement $(\beta=.44, p<.001)$ also made an additional significant contribution to pain-related impairment after controlling for sex $(\beta=-0.11, p<.05)$, pain $(\beta=0.23, p<.001)$, and dispositional disengagement $(\beta=0.27, p<0.001)$. The higher the disengagement strategy scores, the higher the impairment scores. Surprisingly, a positive association $(\beta=0.16, p<.05)$ was found between the reengagement goal strategy and impairment after controlling for pain $(\beta=0.23, p<0.001)$ and dispositional reengagement (i.e. Goal Reengagement Scale; $\beta=-0.44, p<.001$ ). Age was not entered in any of the equations to predict pain-related impairment.
Table 3 Results of multiple regression analyses predicting pain-related impairment

\begin{tabular}{|c|c|c|c|c|c|}
\hline Step and variables & Total $R^{2}$ & $\Delta R^{2}$ & $F$ for model & $\mathrm{B}[95 \% \mathrm{CI}]$ & $\beta$ \\
\hline Step 1 & .100 & & $10.50 * *$ & & \\
\hline Age & & & & & $-.05^{\mathrm{a}}$ \\
\hline Sex & & & & $1.22[.29,2.15]$ & $.13^{*}$ \\
\hline Pain intensity & & & & $.65[.39, .91]$ & $.25 * *$ \\
\hline Step 2 & .196 & 0.10 & & & \\
\hline Tenacious Goal Scale & & & & $-.09[-.14,-.05]$ & $-.21 * *$ \\
\hline Step 3 & .363 & 0.17 & & & \\
\hline Persistence strategy ${ }^{\mathrm{b}}$ & & & & $-.63[-.78,-.47]$ & $-.43^{* *}$ \\
\hline \multicolumn{6}{|l|}{ Step 1} \\
\hline Age & & & & & -.07 \\
\hline Sex & & & & & .10 \\
\hline Pain intensity & & & & $.67[.37, .98]$ & $.25 * *$ \\
\hline Step 2 & .142 & 0.05 & & & \\
\hline Flexible Goal Scale & & & & $-.13[-.21,-.05]$ & $-.19^{*}$ \\
\hline Step 3 & .180 & 0.04 & & & \\
\hline Flexibility strategy ${ }^{\mathrm{b}}$ & & & & $-.35[-.54,-.15]$ & $-.20^{* *}$ \\
\hline \multicolumn{6}{|l|}{ Step 1} \\
\hline Age & & & & & -.12 \\
\hline Sex & & & & $.97[.09,1.85]$ & $.11 *$ \\
\hline Pain intensity & & & & $.59[.34, .84]$ & $.23 * *$ \\
\hline Step 2 & .274 & 0.18 & & & \\
\hline Goal Disengagement Scale & & & & $.36[.22, .49]$ & $.27 * *$ \\
\hline Step 3 & .437 & 0.16 & & & \\
\hline Disengagement strategy ${ }^{\mathrm{b}}$ & & & & $.65[.50, .81]$ & $.44 * *$ \\
\hline \multicolumn{6}{|l|}{ Step 1} \\
\hline Age & & & & & -.06 \\
\hline Sex & & & & & .10 \\
\hline Pain intensity & & & & $.61[.33, .89]$ & $.23 * *$ \\
\hline Step 2 & .262 & 0.16 & & & \\
\hline Goal Reengagement Scale & & & & $-.39[-.49,-.29]$ & $-.44 * *$ \\
\hline Step 3 & .286 & 0.03 & & & \\
\hline Reengagement strategy ${ }^{\mathrm{b}}$ & & & & $.32[.11, .53]$ & $.16^{*}$ \\
\hline
\end{tabular}




\section{Goal management strategies as predictors of psychological well-being}

Table 4 shows the result of multiple regression analyses predicting psychological well-being. After controlling for demographic variables (age and sex) and pain intensity, all the variables in the analysis significantly contributed to the psychological well-being scores, with the exception of the situational reengagement goal strategy. The persistence strategy $(\beta=0.28, p<.001)$ made an additional significant contribution to the prediction of psychological well-being, after controlling for sex $(\beta=-0.16, p<.05)$, pain intensity $(\beta=-0.28, p<.001)$, and dispositional persistence $(\beta=0.37, p<.001)$. The higher the persistence scores, the higher the psychological well-being scores. A similar result was obtained for flexibility $(\beta=0.15, p<.05)$ after controlling for sex $(\beta=-0.11, p<.05)$, pain $(\beta=-0.24$, $p<.001)$, and dispositional flexibility $(\beta=0.40, p<.001)$. Disengagement also significantly predicted psychological well-being $(\beta=-0.32, p<.001)$ after controlling for sex $(\beta=-0.14, p<.05)$, pain $(\beta=-0.27, p<.001)$, and dispositional disengagement $(\beta=-0.37, p<.001)$. The lower the disengagement strategy scores, the higher the psychological well-being scores. After controlling for sex $(\beta=-0.13, p<.05)$, pain $(\beta=-0.25, p<.001)$, and dispositional reengagement $(\beta=0.55, p<.001)$, the reengagement strategy did not make a significant contribution to
Table 4 Results of multiple regression analyses predicting psychological well-being

\begin{tabular}{|c|c|c|c|c|c|}
\hline Step and variables & Total $R^{2}$ & $\Delta R^{2}$ & $F$ for model & $\mathrm{B}[95 \% \mathrm{CI}]$ & $\beta$ \\
\hline Step 1 & .124 & & $13.17 * *$ & & \\
\hline Age & & & & & $.07^{\mathrm{a}}$ \\
\hline Sex & & & & $-8.59[-13.99,-3.19]$ & $-.16^{*}$ \\
\hline Pain intensity & & & & $-4.33[-5.85,-2.82]$ & $-.28 * *$ \\
\hline Step 2 & .318 & 0.19 & & & \\
\hline Tenacious Goal Scale & & & & $.99[.72,1.25]$ & $.37 * *$ \\
\hline Step 3 & .388 & 0.07 & & & \\
\hline Persistence strategyb & & & & $2.43[1.53,3.34]$ & $.28 * *$ \\
\hline \multicolumn{6}{|l|}{ Step 1} \\
\hline Age & & & & & .05 \\
\hline Sex & & & & $-6.27[-12.04,-.50]$ & $-.11 *$ \\
\hline Pain intensity & & & & $-3.75[-5.37,-2.12]$ & $-.24 * *$ \\
\hline Step 2 & .290 & 0.17 & & & \\
\hline Flexible Goal Scale & & & & $1.62[1.19,2.06]$ & $.40 * *$ \\
\hline Step 3 & .310 & 0.02 & & & \\
\hline Flexibility strategy ${ }^{\mathrm{b}}$ & & & & $1.52[.45,2.58]$ & $.15^{*}$ \\
\hline \multicolumn{6}{|l|}{ Step 1} \\
\hline Age & & & & & .08 \\
\hline Sex & & & & $-7.92[-13.11,-2.74]$ & $-.14^{*}$ \\
\hline Pain intensity & & & & $-4.29[-5.77,-2.81]$ & $-.27 * *$ \\
\hline Step 2 & .352 & 0.23 & & & \\
\hline Goal Disengagement Scale & & & & $-2.93[-3.72,-2.14]$ & $-.37 * *$ \\
\hline Step 3 & .437 & 0.09 & & & \\
\hline Disengagement strategy ${ }^{\mathrm{b}}$ & & & & $-2.81[-3.73,-1.90]$ & $-.32 * *$ \\
\hline \multicolumn{6}{|l|}{ Step 1} \\
\hline Age & & & & & .09 \\
\hline Sex & & & & $-6.96[-12.46,-1.47]$ & $-.13^{*}$ \\
\hline Pain intensity & & & & $-3.87[-5.42,-.33]$ & $-.25^{* *}$ \\
\hline Step 2 & .374 & 0.25 & & & \\
\hline Goal Reengagement Scale & & & & $2.72[2.18,3.27]$ & $.51 * *$ \\
\hline Step 3 & .372 & 0.00 & & & \\
\hline Reengagement strategy ${ }^{\mathrm{b}}$ & & & & & -.01 \\
\hline
\end{tabular}


psychological well-being. Age was not entered in any of the equations to predict psychological well-being.

\section{Situational reengagement strategies in the vignettes as predictors of daily functioning, pain-related impairment, and psychological well-being}

Taking into account the pattern of results obtained for the reengagement goal strategy in all the analyses, a complementary set of multiple regression tests was performed on the same criterion variables. The predictors were the Goal Reengagement Scale scores (entered at step 2) and the situational reengagement strategy scores for every vignette (entered at step 3), after controlling for age, sex, and painintensity (entered at step 1).

Only sex $(\beta=0.12, p<.05)$ and pain intensity $(\beta=-0.32$, $p<001)$ were entered into the equation predicting daily functioning. After controlling for dispositional reengagement in the second step $(\beta=0.22, p<.001)$, none of the scores of the reengagement strategies (i.e. independent functioning domain vignette, work competence domain vignette, social/ relationships domain vignette) made a significant contribution to daily functioning.

Regarding pain-related impairment, only age ( $\beta=-0.11$, $p<.05)$ and pain intensity $(\beta=0.23, p<.001)$ were entered in the first step in the equation. After controlling for dispositional reengagement $(\beta=-0.37, p<.001)$, only the reengagement strategy scores for the independent functioning domain vignette $(\beta=0.24, p<.001)$ made a significant contribution to pain-related impairment $\left(R^{2}\right.$ change $=0.06$, $p<.05)$. The higher the scores of the reengagement strategy for the independent functioning domain, the higher the impairment scores.

Finally, after controlling for age $(\beta=0.11, p<.05)$, sex $(\beta=-0.12, p<.05)$, pain intensity $(\beta=-0.24, p<.001)$, and dispositional reengagement $(\beta=0.48, p<.001)$, only the reengagement strategy scores for the independent functioning domain vignette $(\beta=-0.15, p<.01)$ again made a significant contribution to pain-related impairment $\left(R^{2}\right.$ change $=0.02, p<.05)$. The lower the scores of the reengagement strategy for the independent functioning domain, the higher the psychological well-being scores.

\section{Discussion}

This study tested the independent contribution of pain goal management strategies, as measured through vignettes, to the level of daily functioning, pain-related impairment, and psychological well-being of individuals with chronic MSK pain after controlling for the effects of the responses to dispositional measures. Based on the integrated model of goal management $[15,16]$ and on the four goal adjustment strategies proposed by Arends et al. [15], it was assumed that the responses of individuals with chronic MSK pain to vignettes showing a realistic and recognisable situation in which a valued goal is threatened could help to understand how they cope with setbacks in the process of goal striving. Such information could be of help in developing interventions aimed at achieving more realistic goals thus resulting in a higher quality of life for these individuals. Since people in chronic pain experience significant goal disruption, it is relevant to their well-being that they can adjust their life goals. The assessment of such goal self-regulation depends on the availability of valid and reliable tools.

Overall, our results showed that goal strategies significantly contributed to explain the pain adjustment (i.e. daily functioning, pain-related impairment, and psychological well-being) of individuals with chronic MSK pain. More specifically, it was predicted that situational reengagement, disengagement, persistence, and flexibility goal-management strategies would predict daily functioning, pain-related impairment, and psychological well-being after controlling for the effects of demographic variables (age and sex), pain intensity, and scores on goal-management dispositional scales. As far as we know, this study is the first to address these objectives.

As predicted, our findings demonstrate that persistence, flexibility, reengagement, and disengagement goal strategies were significant predictors of pain-related impairment. In addition, all these strategies, with the exception of flexibility, significantly predicted daily functioning. Likewise, all these situational goal-management strategies, with the exception of reengagement, predicted the psychological well-being of people with chronic MSK pain.

As suggested by Esteve et al. [6], successful adaptation when coping with chronic pain requires combining tenacity (i.e. persistence) with a certain amount of flexibility. According to the dual process model [17, 18], whereas persistence is used to maintain goals, flexibility is used to promote adjustment of goals when situations change. The results of the present study showed that the situational persistence goal strategy positively and significantly predicted daily functioning and psychological well-being, whereas it negatively and significantly predicted the scores on painrelated impairment. These findings are consistent with those obtained by Ramírez-Maestre et al. [1], who found that persistence was associated with higher levels of purpose in life in individuals with chronic MSK pain. However, these authors only used the tenacious goal pursuit scale in their study. Our results have shown that the persistence strategy, as measured by vignettes, also contributes to predicting pain adjustment in individuals with chronic MSK pain.

The flexibility strategy is a component of the accommodation process in the dual process model $[17,18]$. This 
strategy involves changing one's goals in order to take into account personal limitations regarding what can be realistically achieved. Although scarce, there are findings that show that flexible goal adjustment promotes quality of life of people with chronic pain [28]. In line with these results, in the present study, flexibility goal management strategy significantly predicted higher scores on psychological wellbeing and lower scores on pain-related impairment. Unexpectedly, no association was found between this strategy and daily functioning. However, the dispositional measure (i.e. the flexible goal management scale) was able to predict functioning. Nevertheless, a recent study on a sample of individuals with chronic MSK pain [29] showed that, compared to other activity patterns, there was little use of pacing (i.e. dividing daily activities into smaller tasks) to increase activity levels and to conserve energy for valued activities. As pacing implies some flexibility, it could be the case that, in the face of hypothetical scenarios representing real situations, people diagnosed with chronic MSK pain tend to respond by choosing those goal management strategies that they employ most frequently in their daily lives. In any case, this speculation deserves empirical study.

On the other hand, the goal adjustment model [19] suggests that adjustment entails both disengaging from unattainable goals and reengaging in alternative goals. Research has demonstrated that disengagement and reengagement capacity are related to different aspects of well-being [11]. Furthermore, it has been pointed out that the perception of real alternatives to a given situation could facilitate disengagement from unattainable goals and reengagement with new goals [6]. Consequently, disengagement would be an adaptive goal management strategy only when it is accompanied by reengagement [1]. In fact, the study by Arends et al. [16] demonstrated that among individuals with rheumatoid arthritis the solutions that involved the disengagement of goals were the least preferred compared to solutions involving goal maintenance, goal adjustment, and goal reengagement. Similarly, in the study by Esteve et al. [6] with a sample of individuals with chronic MSK pain demonstrated that in the face of unattainable goals, people with chronic pain and higher levels of pessimism reported that they tended to abandon such goals. Moreover, goal disengagement was shown to be highly and positively associated with activity avoidance. In line with these results, and as predicted, our findings showed that the disengagement strategy was a significant positive predictor of pain-related impairment and a significant negative predictor of both daily functioning and psychological well-being. Thus, the abandoning of life purposes (even if they seem unattainable) entails negative consequences, because this strategy implies avoidance and avoidance leads to pain chronicity [30].

The strategy of goal reengagement has been thought to promote well-being by fostering purpose in life [11]. Indeed, the goal adjustment model [19] considers reengagement to be an appropriate strategy at all times and that it complements existing goals or replaces unattainable goals [15]. In line with this model, some studies have demonstrated that in the face of unattainable goals, patients with chronic MSK pain who are characterized by higher levels of optimism tended to employ a reengagement goal management strategy, given that they were more able to commit to new goals [1, 6]. However, in the present study, the multiple regression analyses showed conflicting results between the dispositional measure of reengagement (i.e. Goal Reengagement Scale) and the situational one (i.e. vignettes). Thus, as expected, the scores on the Goal Reengagement Scale positively predicted daily functioning and psychological well-being and negatively predicted impairment. In contrast, the reengagement strategy in the vignettes was positively related to impairment and negatively to daily functioning, and did not predict psychological well-being. Nevertheless, the results varied depending on the vignette in question.

Thus, the situational reengagement strategy made a significant contribution to both pain-related impairment and psychological well-being only in the independent functioning domain vignette, although the signs of the correlations were the opposite of what was expected. A reasonable explanation for these results could be that the description of the situational reengagement strategies in the vignettes did not really reflect the meaning of this goal management skill. In fact, a low correlation was found between the participant's own responses to the vignette and the questionnaire, whereas no correlation was found between the dispositional measure and the participants' response to the main character. An alternate explanation for these findings is that reengagement can take many forms. However, the vignettes contained a very specific alternative that might have been the most obvious reengagement goal for some individuals (i.e. they would reengage but with goals other than those describe in the vignettes). More research is needed to clarify this issue.

Although valid and reliable questionnaires on goal management have been designed to measure general tendencies, individuals may make different decisions in different situations depending on the relevance of the personal issues at stake. In line with this suggestion, the vignettes allowed participants to respond within the context of the particular situations presented, thereby improving the quality of the data. With the exception of flexibility (when considering daily functioning as the criterion) and reengagement, our findings showed that the goal-management strategies presented in the vignettes significantly contributed to predicting pain adjustment (i.e. daily functioning, pain-related impairment, and psychological well-being) in the regression analyses. This result indirectly supports the idea that use of the vignette technique can reduce the influence of socially desirable responses when people 
with MSK chronic pain are asked to assume the role of a case-scenario character rather than when they are asked to answer questions from their own personal viewpoints [31].

This study has a number of limitations and thus the results should be interpreted with caution. First, even though the vignettes used are comparable to natural daily situations, the presented scenarios simulate decisions that patients might take, but they are not the actual decisions a patient would take in a real-life scenario. This is because unforeseen circumstances could influence the actual decisions taken in a real-life scenario and obviously these circumstances cannot be described in the vignettes. Textual descriptions and hypothetical behaviour might not be sufficiently representative of "real-world" phenomena, which could raise concerns about the validity of research findings and conclusions based on them. Second, the study used a cross-sectional study design, which is less useful than an extended longitudinal study to evaluate the long-term outcomes of goal adjustment and how it is associated with psychological adjustment over time. Third, there was just one example of a situation per domain. To increase reliability and generalizability, future research could present multiple vignettes per domain.

\section{Conclusion}

Adaptation to chronic pain is not related to pain itself but to the extent to which pain interferes with everyday life and goals. Because the quality of life of individuals with chronic MSK pain partly depends on their ability to adjust their personal goals, it is relevant to investigate pain-related goal adjustment to achieve a better understanding of the management of goal disruption among patients and of the specific behaviour that underlies their management of specific unattainable goals. Domain-specific vignettes could be a valuable addition to the use of existing questionnaires that measure dispositional goal management. The use of vignettes enables the simultaneous presentation of several contextual factors that represent realistic scenarios in which valued goals are threatened by pain. The results of this approach could be used to improve clinical practice aimed at helping people with chronic MSK pain to better cope with this health condition.

Acknowledgements This research was supported by grants from the Spanish Ministry of Science and Innovation (PSI2013-42512- P), and the Regional Government of Andalusia (HUM-566).

\section{Compliance with ethical standards}

Conflicts of interest The authors declare that they have no conflict of interest.

\section{References}

1. Ramírez-Maestre, C., Esteve, R., López-Martínez, A. E., Serrano-Ibáñez, E. R., Ruiz-Párraga, G. T., \& Peters, M. L. (2019). Goal adjustment and well-being: The role of optimism in patients with chronic pain. Annals of Behavioral Medicine, 53(7), 597-607. https://doi.org/10.1093/abm/kay07020.

2. Cimmino, M. A., Ferrone, C., \& Cutolo, M. (2011). Epidemiology of chronic musculoskeletal pain. Best Practice \& Research Clinical Rheumatology, 25(2), 173-183. https://doi. org/10.1016/j.berh.2007.03.003.

3. Carver, C. S., \& Scheier, M. F. (2003). Three human strengths. In L. G. Aspinwall \& U. M. Staudinger (Eds.), A psychology of human strengths: Fundamental questions and future directions for a positive psychology (pp. 87-102). Washington, DC: American Psychology Association.

4. Rasmussen, H. N., Wrosch, C., Scheier, M. F., \& Carver, C. S. (2006). Self-Regulation processes and health: The importance of optimism and goal adjustment. Journal of Personality, 74(6), 1721-1747. https://doi.org/10.1111/j.1467-6494.2006.00426.x.

5. Crombez, G., Lauwerier, E., Goubert, L., \& Van Damme, S. (2016). Goal pursuit in individuals with chronic pain: A personal project analysis. Frontiers in Psychology, 7, 966. https:// doi.org/10.3389/fpsyg.2016.00966.

6. Esteve, R., López-Martínez, A. E., Peters, M. L., SerranoIbáñez, E. R., Ruiz-Párraga, G. T., \& Ramírez-Maestre, C. (2018). Optimism, positive and negative affect, and goal Adjustment strategies: Their relationship to activity patterns in patients with chronic musculoskeletal pain. Pain Research and Management. https://doi.org/10.1155/2018/6291719.

7. Esteve, R., Ramírez-Maestre, C., Peters, M. L., Serrano-Ibáñez, E. R., Ruiz-Párraga, G. T., \& López-Martínez, A. E. (2016). Development and initial validation of the Activity Patterns Scale in patients with chronic pain. Journal of Pain, 17(4), 451-461. https://doi.org/10.1016/j.jpain.2015.12.009.

8. Karoly, P., Okun, M. A., Enders, C., \& Tennen, H. (2014). Effects of pain intensity on goal schemas and goal pursuit: A daily diary study. Health Psychology, 33(9), 968-796. https:// doi.org/10.1037/hea0000093.

9. Karsdorp, P. A., \& Vlaeyen, J. W. (2011). Goals matter: Both achievement and pain-avoidance goals are associated with pain severity and disability in patients with low back and upper extremity pain. Pain, 152(6), 1382-1390. https://doi. org/10.1016/j.pain.2011.02.018.

10. Wrosh, C., Scheier, M. F., \& Miller, G. E. (2013). Goal adjustment capacities, subjective well-being, and physical health. Social and Personal Psychology Compass, 7(12), 847-860. https://doi.org/10.1111/spc3.12074.

11. Mens, M. G., \& Scheier, M. (2015). The benefits of goal adjustment capacities for well-being among women with breast cancer: Potential mechanisms of action. Journal of Personality, 84(6), 777-788.

12. Atzmüller, C., \& Steiner, P. M. (2010). Experimental vignette studies in survey research. Methodology, 6(3), 128-138. https ://doi.org/10.1027/1614-2241/a000014.

13. De Ruddere, L., Bosmans, M., Crombez, G., \& Goubert, L. (2016). Patients are socially excluded when their pain has no medical explanation. Journal of Pain, 17(9), 1028-1035. https ://doi.org/10.1016/j.jpain.2016.06.005.

14. Goubert, L., Vervoort, T., De Ruddere, L., \& Crombez, G. (2012). The impact of parental gender, catastrophizing and situational threat upon parental behaviour to child pain: A vignette study. European Journal of Pain, 16(8), 1176-1184. https://doi. org/10.1002/j.1532-2149.2012.00116.x. 
15. Arends, R. Y., Bode, C., Taal, E., \& van de Laar, M. A. (2013). The role of goal management for successful adaptation to arthritis. Patient Education Counselling, 93(1), 130-138. https://doi. org/10.1016/j.pec.2013.04.022.

16. Arends, R. Y., Bode, C., Taal, E., \& van de Laar, M. A. (2015). Exploring preferences for domain-specific goal management in patients with polyarthritis: What to do when an important goal becomes threatened? Rheumatology International, 35(11), 18951907. https://doi.org/10.1007/s00296-015-3336-8.

17. Brandtstädter, J., \& Renner, G. (1990). Tenacious goal pursuit and flexible goal adjustment: Explication and age-related analysis of assimilative and accommodative strategies of coping. Psychology and Aging, 5(1), 58-67. https://doi.org/10.1006/drev.2001.0539.

18. Brandtstädter, J., \& Rothermund, K. (2002). The life-course dynamics of goal pursuit and goal adjustment: A two-process Framework. Developmental Review, 22(1), 117-150.

19. Wrosch, C., Scheier, M. F., Miller, G. E., Schulz, R., \& Carver, C. S. (2003). Adaptive self-regulation of unattainable goals: Goal disengagement, goal reengagement, and subjective well-being. Personality and Social Psychological Bulleting, 29(12), 14941508. https://doi.org/10.1177/0146167203256921.

20. Holley, J., \& Gillard, S. (2018). Developing and using vignettes to explore the relationship between risk management practice and recovery-oriented care in mental health services. Qualitative Health Research, 28(3), 371-380. https://doi.org/10.1177/10497 32317725284.

21. Jensen, M. P., Turner, J. A., Romano, J. M., \& Strom, S. E. (1995). The Chronic Pain Coping Inventory: Development and preliminary validation. Pain, 60(2), 203-216. https://doi. org/10.1016/0304-3959(94)00118-X.

22. Soubrier, E., Esteve, R., \& Ramírez-Maestre, C. (2017). Adaptación de las escalas "Tenacious Goal Pursuit", "Flexible Goal Adjustment" y "Goal Disengagement and Goal Reengagement". Escritos de Psicología /Psychological Writings, 10(2), 103-115. https://doi.org/10.5231/psy.writ.2017.2003.

23. Ramírez-Maestre, C., \& Esteve, R. (2015). A new version of the Impairment and Functioning Inventory for patients with chronic pain (IFI-R). $P M \& R, 7(5), 455-465$. https://doi.org/10.1016/j. pmrj.2014.11.013.

24. Lucas-Carrasco, R. (2012). Reliability and validity of the Spanish version of the World Health Organization-Five Well-Being Index in elderly. Psychiatry Clinical Neuroscience, 66(6), 508-513. https://doi.org/10.1111/j.1440-1819.2012.02387.x.

25. Björnsdóttir, S. V., Jónsson, S. H., \& Valdimarsdóttir, U. A. (2014). Mental health indicators and quality of life among individuals with musculoskeletal chronic pain: A nationwide study in Iceland. Scandinavian Journal of Rheumatology, 43(5), 419-423. https://doi.org/10.3109/03009742.2014.881549.

26. Cohen, J. W. (1988). Statistical power analysis for the behavioral sciences. Hillsdale, NJ: Lawrence Erlbaum Associates.

27. Tabachnick, B. G., \& Fidell, L. S. (2007). Using multivariate statistics. Boston, MA: Pearson/Allyn and Bacon.

28. Schmitz, U., Saile, H., \& Nilges, P. (1996). Coping with chronic pain: Flexible goal adjustment as an interactive buffer against pain-related distress. Pain, 67(1), 41-51. https://doi. org/10.1016/0304-3959(96)03108-9.

29. Esteve, R., López-Martínez, A. E., Peters, M. L., Serrano-Ibáñez, E. R., Ruiz-Párraga, G. T., González-Gómez, H., et al. (2017). Activity pattern profiles: relationship with affect, daily functioning, impairment, and variables related to life goals. Journal of Pain, 18(5), 546-555. https://doi.org/10.1016/j.jpain.2016.12.013.

30. Asmundson, G. J., Norton, P. J., \& Norton, G. R. (1999). Beyond pain: The role of fear and avoidance in chronicity. Clinical Psychology Review, 19(1), 97-119.

31. Hughes, R., \& Huby, M. (2002). The application of vignettes in social and nursing research. Journal of Advanced Nursing, 37(4), 382-386. https://doi.org/10.1046/j.1365-2648.2002.02100.x.

Publisher's Note Springer Nature remains neutral with regard to jurisdictional claims in published maps and institutional affiliations. 